\title{
COMUNICAÇÃO POR VÍDEO COMO FERRAMENTA DE ENGAJAMENTO NA EAD
}

\author{
SÃO PAULO/SP MAIO/2018
}

\author{
Maria Cristina Uchida de Aguiar - EAD Laureate - mcaguiar@eadlaureate.com.br \\ Giovani Pereira dos Santos - EAD Laureate - gpsantos@eadlaureate.com.br \\ Nayara Alves Carreira - EAD Laureate - nacarreira@eadlaureate.com.br \\ Wagner da Silva Alves - EAD Laureate - wdalves@eadlaureate.com.br \\ Jackeline Ferreira da Encarnacao - EAD Laureate - jackeproreitoria@gmail.com
}

\author{
Tipo: Relato de Experiência Inovadora (EI) \\ Categoria: Métodos e Tecnologias \\ Setor Educacional: EDUCAÇÃO SUPERIOR
}

\begin{abstract}
RESUMO
Apesar dos avanços tecnológicos aplicados no Ensino a Distância, há de se considerar que ainda existe uma separação física nesta modalidade de ensino e, com isso, surgem espaços a serem transpostos. Diante deste cenário, este artigo tem por objetivo evidenciar a aplicabilidade da comunicação por meio de vídeos e mostrar como sua utilização efetiva contribui para o engajamento do estudante na modalidade EaD. Para tanto, procede-se pesquisa bibliográfica e abordagem quantitativa. Deste modo, observa-se que a utilização de vídeos melhora o processo de comunicação entre estudante e professor, o que permite concluir que, existe uma grande oportunidade de docentes e tutores explorarem o engajamento estudantil por meio de vídeos, desde que utilizados de formas adequadas - formas estas que serão exploradas diante dos diversos cenários possíveis apresentados ao longo do material.
\end{abstract}

Palavras-chave: EAD; Tecnologia; Vídeos; Engajamento 


\section{EAD ONLINE}

A educação online está presente em diversos países e faz parte da realidade mundial.

Por meio da educação online, muitos problemas são facilmente resolvidos, como no caso de um deficiente físico, por exemplo, em que estudar na modalidade online, para ele, uma dinâmica teoricamente mais simples, quando pode se apropriar dos conteúdos a serem estudados em seu computador dentro do conforto de sua casa. Indubitavelmente, aqueles que decidem buscar a sua formação por meio do ensino a distância, certamente enfrentarão desafios ao longo do curso e, devem saber, que o ensino a distância exige uma postura diferenciada de seus. A autonomia, proatividade, organização e responsabilidade são alguns dos itens indispensáveis na modalidade, e o aprendizado online, pelo contrário do que muitos por vezes imaginam, pode exigir muito mais tempo do estudante, além de um maior nível e qualidade de concentração.

Escolheu-se utilizar o termo educação online e não educação a distância, graças aos avanços em termos de recursos tecnológicos atuais. Atualmente, na educação online, é disponibilizado ao estudante uma plataforma de estudos em que estão reunidas todas as mídias necessárias para o desenvolvimento do curso e aprendizado. Segundo Belloni, "a

terceira geração de EaD começa a surgir nos anos de 1990, como desenvolvimento e disseminação das novas tecnologias de informação e comunicação (NTIC), sendo muito mais uma proposta a realizar do que propriamente uma realidade a analisar. Seus meios principais são, ou, serão todos os anteriores mais os novos, o que implicará mudanças radicais nos modos de ensinar e aprender. " (BELLONI, 2012, p. 62).

Os avanços das tecnologias permitiram a utilização de variadas mídias, entre elas textos, videoaulas, chats, webconferências, fóruns de discussão etc., e também possibilitou uma maior interatividade e aproximação entre estudantes e equipe pedagógica.

A partir do desenvolvimento das NTIC, pode-se pensar em um novo formato de ensinoaprendizagem, um formato "aberto", baseado no aluno e em resultado e um ambiente interativo, que permite a construção do conhecimento por meio da participação do aluno e a mediação do professor, "saber 'mediatizar' será uma das competências mais importantes e indispensáveis à concepção e realização de qualquer ação de EaD”. (BELLONI, 2012, p. 67) 
Durante o período de vigência dos conteúdos, respeitando-se os prazos de início e término, o estudante pode ter a sua aula no momento que julgar mais adequado. Em aprendizados com o uso da informática, é importante que um dos atores essenciais para o processo de aprendizagem online tenha consciência do seu papel enquanto educador e agente transformador: o professor. Segundo Moran, "estamos caminhando para um conjunto de situações de educação online plenamente audiovisuais. Caminhamos para processos de comunicação audiovisuais, com possibilidade de forte interação, integrando o que de melhor conhecemos da televisão (qualidade da imagem, som, contar estórias, mostrar ao vivo) com o melhor da internet (acesso a banco de dados, pesquisa individual e grupal, desenvolvimento de projetos em conjunto, a distância, apresentação de resultados). Tudo isso exige uma pedagogia muito mais flexível, integradora e experimental diante de tantas situações novas que começamos a enfrentar. Não podemos confundir a educação online só com cursos pela internet no modo texto." (MORAN, 2006, p. 45)

Ter consciência deste papel e se sentir agente fundamental de mudanças são características que transformam e motivam as ações e que, a partir deste novo olhar, traz à tona o reconhecimento do inestimável valor da arte de educar.

\section{HUMANIZAÇÃO NAS PLATAFORMAS DO EAD}

Esta modalidade de aprendizagem, traz junto a si, novas organizações de espaço, tempo e mídias. Mas, na atualidade, onde denota-se o grande espaço ocupado pelo $E A D$, tomar como meta a escolha de ferramentas para agregar um ensino aprendizagem adequado é um grande desafio. Chamar o estudante proveniente do ensino presencial e ofertar nova e diferente metodologia, requer mudanças na forma de comunicação.

Segundo Moore (1993), "O sucesso do ensino a distância depende da criação, por parte da instituição e do instrutor, de oportunidades adequadas para o diálogo entre professor e aluno, bem como de materiais didáticos adequadamente estruturados." (MOORE, 1993, p. 6).

A educação on-line envolve a utilização de recurso tecnológico como meio didático. Todavia, para Silva e Figueiredo (2012), a falta de sincronia entre a utilização de uma ferramenta tecnológica e a ausência do convívio aluno professor, não deve ser elemento caracterizante de exclusão dos relacionamentos sociais no EAD.

A necessidade e importância da humanização na EAD, chama por elementos que tragam proximidade entre estudante e professor, além do estímulo à aprendizagem, do 
prazer de compreender e conhecer aquilo a que se propôs.

Vygotsky (1996) considera que, é na compreensão da base afetiva da pessoa, o entendimento o pensamento humano. Assim, razões dão impulso ao pensamento que encontram seu princípio na emoção que a constrói. Neste ponto, emerge a estreita relação entre afetividade e cognição, gerando o processo do conhecimento. Assim sendo, é fundamental instrumentos que mobilizem a afetividade e, consequentemente, a motivação.

De acordo com Rocha (2016), no contexto humanização do EAD, ainda são diversas as dificuldades na implementação de ações para a contribuição no avanço da educação mediada e a distância. Segundo o autor, especialistas afirmam que a humanização se baseia na linguagem natural, composta por expressões que são próprias do ser humano, dentro do que o representa, do que lhe dá garantia em sua forma de comunicação nas relações sociais, em diversos momentos como sofrimento, angústia, comunicação e, até mesmo, aprendizagem.

Ao citar as diferenças pedagógicas entre as mídias, (BATES, 2016, p. 307) afirma ser o vídeo "uma mídia mais rica, quando comparado ao texto e áudio, pois, além de ofertar som e texto, também disponibiliza imagens dinâmicas ou em movimento."

Quando mencionamos vídeos, é importante pontuar que não nos referimos a videoaulas ou webconferências em si, mas àqueles onde, em espaço definido, faz um chamamento direto ao estudante ao trazer sua atenção para a realização de atividades, atenção a prazos, orientações pontuais e demais avisos/comunicados que vão nortear seu caminho ao longo do processo de aprendizagem, no sentido de se ter um interlocutor diretamente se comunicando por meio de imagem, movimento e som.

Os vídeos geram situações antagônicas e diferenciais, quebram as vertentes do aprendizado voltado somente a textos, quando, por exemplo, elaborado trazendo um novo sentido para a mensagem, com a sensação de pertencimento, aproximação, de não estar só, frente a um sem número de elementos aos quais se depara a serem estudados.

\section{A UTILIZAÇÃO DE VÍDEO NO PROCESSO DE ENSINO APRENDIZAGEM}

Dias e Cavalcanti (2017), nos apresenta a mudança intrínseca do advento da internet com a evolução dos meios de comunicação tão valorizados na atualidade. A tecnologia promoveu tanto a adesão necessária quanto os meios a difusão social e aderência às 
mídias. Tal perspectiva não deve ser ignorada no ambiente educacional, em que deve ser percebido como uma extensão da vida cotidiana do indivíduo e natural de sua interação com o mundo digital.

Já em 2010, o IBOPE promoveu uma pesquisa sobre redes sociais analisando o engajamento dos usuários frente as demandas promovidas pelas interações na rede. Nesta pesquisa indicada na Figura 1, o resultado de $96 \%$ de audiência dos que utilizam as redes é aspecto relevante a se considerar, demonstrando a disponibilidade dos usuários para a recepção de conteúdos.

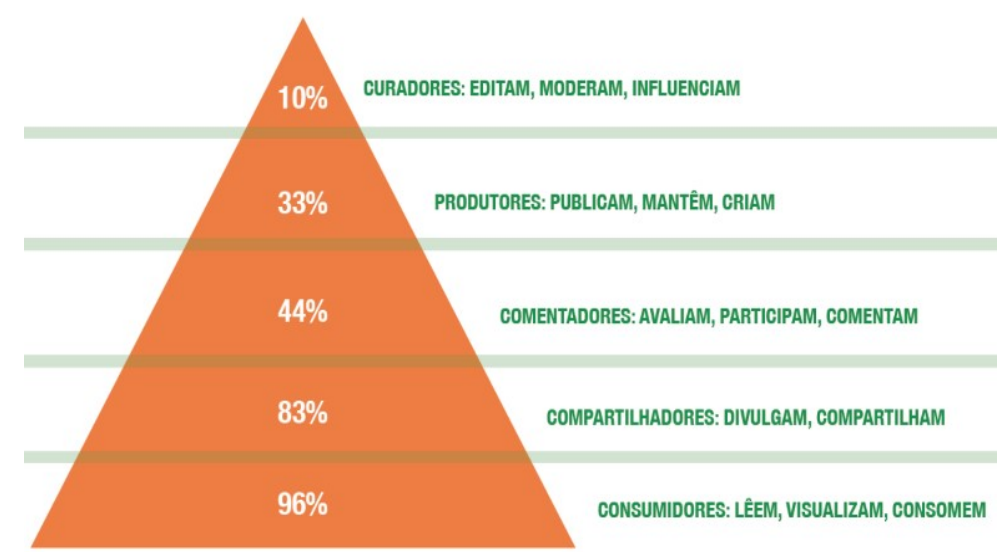

Figura 1: Engajamento Redes Sociais. Fonte: ibope (2010)

Nessa análise, há espaço para o protagonismo institucional, e a escolha correta dos meios de comunicação podem engajar o interesse de estudantes nos conteúdos programáticos da educação online e no ensino presencial.

A velocidade impera sobre a disponibilidade. Manfrim et al (2014), ressalta que o ensino audiovisual tem um potencial enorme de estimular o engajamento criativo de estudantes, abre espaço para descobertas, atiça a curiosidade em âmbitos diversos.

Ao deslumbrarmos a junção dos meios de comunicação sob demanda, os dispositivos móveis e o interesse pelas plataformas de vídeos, há dezenas de possibilidades para a educação online, tanto para a gestão e disponibilização de conteúdo quanto para comunicação síncrona ou assíncrona com os estudantes.

Se considerarmos a Pirâmide de Aprendizagem de William Glasser, que apresenta a capacidade de assimilar conteúdos a partir do meio em que este conhecimento é apresentado, a categoria que compreende "quando vermos e ouvimos" pode promover $50 \%$ de assimilação do conteúdo. 


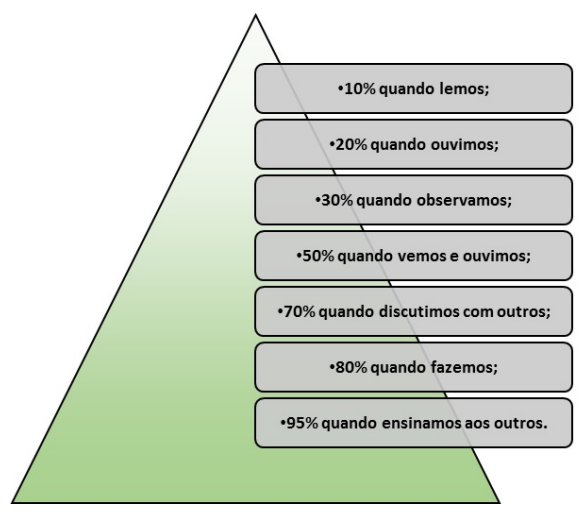

Figura 2 Pirâmide de Aprendizagem de William Glasser

Segundo Mota e Tamaizzo (2014), a força da imagem é tendência em diversos segmentos, tornando-se substituto inclusive de textos, já que "o visual é de mais fácil assimilação, vídeos curtos com mensagens diretas também ganham espaço" nesse cenário em que o volume de informação é crescente na internet. Com todas essas tendências, a comunicação direta, por meio de imagens, aproxima os estudantes e humaniza a relação Professor-Estudantes, Tutor-Estudante e Estudante-Instituição de ensino.

\section{METODOLOGIA}

Para atender aos objetivos de pesquisa, adotou-se a abordagem quantitativa. Os autores Terence e Escrivão Filho (2006) a definem como conciliação de ideias empiristas que alia os conceitos de matemática e lógica. Esta investigação teve como característica a pesquisa descritiva, pois buscou-se descrever as percepções dos estudantes em relação aos vídeos postados no AVA - Ambiente Virtual de Aprendizagem. Como técnica de coleta de dados, utilizou-se o questionário. Para Collis e Hussey (2005, p. 165), "um questionário é uma lista de perguntas cuidadosamente estruturadas, escolhidas após a realização de vários testes, tendo em vista extrair respostas confiáveis de uma amostra escolhida". Entre os vários modelos de questionários existentes, optou-se por questões fechadas tendo em vista a viabilização de tabulação dos dados.

O questionário foi elaborado por meio da ferramenta Google Docs, disponibilizado no formando online e inserido em disciplinas do AVA para que os estudantes pudessem responder. As questões foram divididas em duas seções: a primeira, para avaliar a percepção dos estudantes em relação aos vídeos de engajamento e, a segunda seção, para avaliar a percepção dos estudantes em relação aos vídeos inseridos que faziam relação com as atividades avaliativas, sempre com cunho pedagógico. 
O tipo de pesquisa aplicada foi de campo, visto que os dados foram coletados diretamente com os estudantes. A amostra para este estudo envolveu 1.005 estudantes regularmente matriculados no primeiro semestre de 2018, nos cursos de graduação voltados para a área de negócios na modalidade a distância. Como técnica de tratamento dos dados, utilizou-se planilha eletrônica Microsoft Excel e, para a análise dos dados, empregou-se a estatística descritiva simples.

\section{DISCUSSÃO DOS RESULTADOS}

questionário foi aplicado para uma amostra de 1.005 estudantes, sendo disponibilizado no período de 06 a 17/04/2018. Foram recebidos 129 questionários respondidos, ou seja, $12,83 \%$ do total da amostra.

Em relação ao conjunto de perguntas relacionadas ao engajamento estudantil, foi perguntado ao estudante: "Qual o formato de avisos que você prefere?" Pouco mais da metade dos estudantes - 71 respondentes, que corresponde a 55\% - informaram que preferem os avisos em formato de vídeo e texto; 35\% informaram que prefere somente em formato de texto; e 10\% prefere em formato de vídeo apenas. Tal escolha vai ao encontro da Pirâmide de Aprendizagem de William Glasser, que significa dizer que 'aprendemos ou assimilamos em algo em $50 \%$ quando estamos expostos visualmente e auditivamente'.

Ao serem questionados sobre a publicação de avisos/comunicados em formato de vídeo na disciplina, $41 \%$ dos estudantes informaram que não foi publicado avisos neste formato nas disciplinas em que estavam matriculados recentemente; $36 \%$ responderam que foi publicado e assistiram; e 23\% informaram que foi publicado, porém, não assistiram. De acordo com as respostas, nota-se que existe uma grande oportunidade para os docentes e tutores de explorarem o engajamento estudantil por meio de vídeos. Segundo Bates (2016), o recurso de audiovisual é uma forma de humanização na educação, pois, além de conciliar texto e áudio, proporciona a dinamicidade do movimento das imagens.

O resultado da questão "O aviso em formato de vídeo contribuiu para a realização das atividades?" Apresentou os seguintes números: $43 \%$ responderam que contribuiu; $15 \%$ respondeu entre 'não assistiu, mas acha que contribuiria' e 'não contribuiu'; e 41\% não responderam à pergunta. Mesmo com um número alto de não respondentes na questão, grande parte dos alunos sinalizaram que o vídeo contribuiu para a realização da tarefa. Tal resposta reforça a teoria de Bates (2016) em que os vídeos apoiam na humanização da educação. 
$\mathrm{Na}$ segunda seção do questionário, em que avalia a percepção dos estudantes em relação aos vídeos voltados para atividades pedagógicas, a pergunta "Foram disponibilizados vídeos no Fórum Avaliativo e/ou na questão dissertativa?" Obteve as seguintes respostas: $67 \%$ informaram que foi disponibilizado e assistiram; $25 \%$ responderam que não foi disponibilizado; e 9\% responderam que foi disponibilizado, no entanto, não assistiram. Tais respostas apontam para duas situações: a primeira relaciona-se com a oportunidade de os docentes explorarem mais o recurso de vídeos por meio de atividades acadêmicas; e, a segunda situação apresentada pelas respostas, do interesse apresentado pelos estudantes em se ter vídeos, quando 67\% deles informaram que assistiram aos vídeos.

$\mathrm{Na}$ última questão, quando se perguntou aos estudantes "O vídeo contribuiu para a melhor compreensão do tema proposto?", mais da metade dos estudantes - neste caso, $76 \%$, responderam que sim, o vídeo contribuiu; $14 \%$ responderam que não assistiram, mas, acha que contribuiria; e 10\% respondeu que não contribuiu. Para grande parte dos alunos, o vídeo foi significativo para a realização da tarefa, e tal fato demonstra que grande parte dos docentes vêm adotando métodos e práticas pedagógicas que vão além dos tradicionais formatos, os quais tem ido ao encontro de um desenvolvimento educativo mais efetivo neste processo de ensino-aprendizagem.

\section{CONCLUSÃO}

Diante das respostas obtidas com o formulário de pesquisa aplicado, bem como com as referências bibliográficas pesquisadas ao longo do artigo, evidencia-se que, de fato, a comunicação feita nos ambientes virtuais de aprendizagem, quando elaboradas por meio de vídeos como ferramenta de engajamento na EAD, tem resultados positivos e instigam os estudantes para atuarem de forma mais ativa, seja por meio da entrega de suas atividades avaliativas ou ao se apropriar mais dos conteúdos disponíveis para estudo na plataforma.

Observa-se que a utilização de vídeos melhora o processo de comunicação entre estudante e professor/tutor, o que permite concluir também que, para aqueles profissionais acadêmicos que ainda não utilizam este recurso como uma forma de comunicação nos (Ambiente Virtuais de Aprendizagem - AVA), podem encontrar oportunidade para explorar tal engajamento.

Estudar a distância não significa a ausência de relações sociais. Percebe-se que os vídeos apoiam a questão da humanização nesta modalidade de ensino por meio de elementos que viabilizam a proximidade entre estudantes e acadêmicos, além de 
estimular à aprendizagem.

Vale ressaltar a velocidade da informação na 'Era do conhecimento', onde impera sobre a disponibilidade e pede, hoje, que se tenham textos mais curtos e pontuais para se ter mais alcance, cabendo o mesmo para a produção de vídeos, onde o ensino audiovisual ganha uma enorme relevância ao estimular não somente o engajamento criativo dos estudantes, mas chamando sua atenção para os conteúdos, abrindo espaço para novas descobertas ao mesmo tempo que desperta a curiosidade em cenários diversos.

Neste contexto contemporâneo, em que a força da imagem passa a ser mais que uma tendência em diversos segmentos e o visual possui assimilação, vídeos curtos com mensagens diretas na educação online ganham seu devido espaço e podem apoiar a tão conhecida 'permanência acadêmica' dos estudantes nos ambientes virtuais de aprendizagem.

\section{REFERÊNCIAS}

ABED - Associação Brasileira de Educação a Distância. Disponível em: . Acesso em: 08 abr 18.

BATES, T. Educar na era digital: design, ensino aprendizagem. São Paulo: Artesanato Educacional, 2016.

BELLONI, M. L. Educação a distância. 6ª ed. Campinas: Autores Associados, 2012.

COLLINS, J.; HUSSEY, R. Pesquisa em Administração. Um guia prático para alunos de graduação e pós-graduação. Porto Alegre: Bookman, 2005. 349 p.

DANTAS; G. E. P.; TORRES, P. A.; COUTINHO, R. E. T. O uso das TICs no ensino Médico: primeiras impressões do projeto 'responda'. Revista de Pesquisa Interdisciplinar, [S.I.], v. 2, set. 2017. Disponível em: . Acesso em: 02 abr. 2018. doi:http://dx.doi.org/10.24219/rpi.v2i2.312.

DIAS, G. A.; CAVALCANTE, R. A. As tecnologias da informação e suas implicações para a educação escolar: Uma conexão em sala de aula. Revista de Pesquisa Interdisciplinar, [S.I.], v. 1, fev. 2017. Disponível em: . Acesso em: 02 abr. 2018. doi:http://dx.doi.org/10.24219/rpi.v1iEsp.80.

IBOPE. O fenômeno das redes sociais no Brasil (2010). Disponível em: . Acesso em: 10 
abr 2018.

LÉVY, P. Cyberculture rapport au conseil de l'europe. Paris: Odile Jacob, 1997.

MANFRIM, A. et al. Cinema e Vídeo em Escolas da Rede Pública de São Paulo: Experiência de Ensino e Aprendizagem. Revista de Cultura e Extensão USP, São Paulo, v. 11, p. 65-72, maio 2014. ISSN 2316-9060. Disponível em: . Acesso em: 02 apr. 2018. doi:http://dx.doi.org/10.11606/issn.2316-9060.v11i0p65-72.

MOORE, M. G. Teoria da Distância Transacional. Revista Brasileira de Aprendizagem Aberta e a Distância. Tradução de Wilson de Azevedo com autorização do autor. Revisão de tradução: José Manuel da Silva. São Paulo, Agosto 2002.

MORAN, J. M. Contribuições para uma pedagogia da educação online. In: SILVA, M. Educação online. $2^{\mathrm{a}}$ ed. São Paulo: Edições Loyola, 2006.

MOTA, L. T. E. Marketing Digital e as Tendências das Redes Sociais em um Futuro Próximo. Trabalho de conclusão do curso de pós-graduação lato sensu à distância em Gestão e Marketing Digital pelo convênio UCDB/ Portal Educação. Campo Grande/MS, 2014. Disponível em: . Acesso em: 02 apr. 2018.

ROCHA, E. F. Humanização da Aprendizagem na EaD (2016). Disponível em: . Acesso em: 02 ago 2017.

SILVA, C. G.; FIGUEIREDO, V. F. Ambiente virtual de aprendizagem: comunicação, interação e afetividade na EAD. (2012). Disponível em: . Acesso em: 01 abr 2018.

TERENCE, A. C. F.; ESCRIVÃO FILHO, E. Abordagem quantitativa, qualitativa e a utilização da pesquisa-ação nos estudos organizacionais. In: XXVI ENEGEP - Fortaleza, Anais... Ceara: Abebro, 2006.

VYGOTSKY, I. S. Teoria e método em psicologia. São Paulo: Martins Fontes, 1996.

YOUTUBE, De Play em Play. (2017). Disponível em: Acesso em: 02 abr. 2018. 